\title{
Irrigação por gotejamento com água residuária tratada da indústria da castanha de caju sob pressões de serviço
}

\section{Drip irrigation with treated wastewater from cashew nut industry under service pressures ${ }^{1}$}

\author{
Ketson Bruno da Silva²; Manuel Januário da Silva Júnior; \\ Rafael Oliveira Batista ${ }^{3 *}$; Delfran Batista dos Santos ${ }^{4}$; \\ Raquel Oliveira Batista ${ }^{5}$; Luis César de Aquino Lemos Filho ${ }^{3}$
}

\section{Resumo}

O aproveitamento agrícola das águas residuárias geradas no processamento da castanha de caju possibilita a racionalização do uso da água, bem como a minimização da poluição e da degradação ambiental. O trabalho objetivou analisar o efeito de pressões de serviço na uniformidade de distribuição de unidades de irrigação por gotejamento aplicando água residuária tratada da castanha de caju. $\mathrm{O}$ experimento foi montado em esquema de parcelas subsubdivididas, tendo nas parcelas as pressões de serviço $(70,140,210$ e $280 \mathrm{kPa})$, nas subparcelas os modelos de gotejadores (G1, G2 e G3) e nas subsubparcelas os períodos das avaliações $(0,20,40,60,80,100,120,140$ e $160 \mathrm{~h}$ de operação das unidades de irrigação). Os tratamentos foram distribuídos em delineamento inteiramente casualizado com três repetições. O coeficiente de uniformidade de distribuição das unidades de irrigação, bem como as características físicas, químicas e microbiológicas do efluente foram determinadas a cada $20 \mathrm{~h}$ de operação das unidades de irrigação até totalizar 160 h. A combinação gotejador G3 e pressão de serviço de $140 \mathrm{kPa}$ proporcionou níveis excelentes da uniformidade de distribuição de efluente nas unidades de irrigação, operando com água residuária tratada da castanha de caju. Para aplicação de água residuária tratada da castanha de caju não é recomendada o uso de gotejadores de baixa vazão nominal $(\leq 1,6 \mathrm{~L}$ $\mathrm{h}^{-1}$ ) e maior comprimento de labirinto ( $\geq 58 \mathrm{~mm}$ ).

Palavras-chave: Reuso, desempenho, emissores, entupimento

\begin{abstract}
The agricultural use of wastewater generated in the processing of cashew nuts enables the rationalization of water use, as well as the minimization of pollution and environmental degradation. The study aimed to analyze the effect of service pressures in the distribution uniformity of drip irrigation units applying treated wastewater from cashew nut industry. The experiment was conducted in split-split plots scheme having the service pressures $(70,140,210$ and $280 \mathrm{kPa})$ on parcels, the emitters models (G1, G2 and
\end{abstract}

\footnotetext{
${ }^{1}$ Parte da Dissertação de Mestrado do primeiro autor apresentada ao Curso de Pós-Graduação em Irrigação e Drenagem, Universidade Federal Rural do Semi-Árido.UFERSA, Mossoró, RN.

2 Discente do Curso de Doutorado em Manejo de Solo e Água, UFERSA, Campus Mossoró, Mossoró, RN. E-mail: ketsonbruno@ hotmail.com

${ }^{3}$ Profs. da UFERSA, Dept ${ }^{\circ}$ de Ciências Ambientais e Tecnológicas, UFERSA, Campus Mossoró, Mossoró, RN. E-mail: mjanuario@ufersa.edu.br; rafaelbatista@ufersa.edu.br; lcalfilho@ufersa.edu.br

4 Prof. do Instituto Federal de Educação, Ciência e Tecnologia Baiano, IF Baiano, Campus Senhor do Bonfim, Senhor do Bonfim, BA. E-mail: delfran.batista@gmail.com

5 Discente do Curso de Doutorado em Solos e Nutrição de Plantas, Universidade Federal de Lavras, UFLA, Campus Universitário, Lavras, MG. E-mail: batista.raqueloliveira@gmail.com

* Autor para correspondência
} 
G3) on subplots and the evaluation periods $(0,20,40,60,80,100,120,140$ and $160 \mathrm{~h}$ of operation of the irrigation units) on subsubplots. The treatments were distributed in a completely randomized design with three replications. The coefficient of uniformity of distribution of irrigation units, as well as the physical, chemical and microbiological characteristics of the effluent were determined every 20 hours of operation the irrigation units to totalize $160 \mathrm{~h}$. The combination of dripper G3 and service pressure of $140 \mathrm{kPa}$ provided excellent levels of distribution uniformity of effluent on irrigation units operating with treated wastewater of cashew nut industry. For application of treated wastewater from cashew nut it is not recommended the use of drippers with low flow rate $\left(\leq 1.6 \mathrm{~L} \mathrm{~h}^{-1}\right)$ and labyrinth of greater length $(\geq 58 \mathrm{~mm})$.

Key words: Reuse, performance, emitter, clogging

\section{Introdução}

No processamento da castanha de caju são geradas águas residuárias nas etapas de lavagem e umidificação da castanha de caju, lavagem dos equipamentos utilizados nos processo industrial e lavagem dos gases no sistema de tratamento de resíduos gasosos (CHEDEVILLE; DEBACQ; PORTE, 2009; LOPES et al., 2011).

O aproveitamento agrícola das águas residuárias geradas no processamento da castanha de caju possibilita a racionalização do uso da água, minimização da poluição e da degradação ambiental, economia de fertilizantes, conservação do solo, preservação dos corpos hídricos e aumento da produção agrícola. Porém, vale ressaltar a importância de um planejamento adequado que possa garantir a utilização dessas águas residuárias de forma segura e funcional na agricultura. Tendo em vista que o Brasil não dispõe de legislação ambiental mais específica para a atividade do reuso, devendo, assim, serem estabelecidas bases política, legais e institucionais para essa atividade.

Os sistemas de irrigação localizada são recomendados para aplicação de águas residuárias por causa da elevada eficiência de aplicação do efluente e do baixo risco de contaminação do produto agrícola e de operadores no campo (SOUZA et al., 2011). No entanto, os sistemas de irrigação por gotejamento possuem emissores que apresentam alta suscetibilidade ao entupimento (DURAN-ROS et al., 2009; LIU; HUANG, 2009). A formação de biofilme nos gotejadores e nas linhas laterais de sistemas de irrigação por gotejamento é o principal problema quando da aplicação de águas residuárias (DAZHUANG et al., 2009; DURAN-ROS et al., 2009; LIU; HUANG, 2009).

$\mathrm{O}$ entupimento dos gotejadores acarreta perdas de vazão e desuniformidade de distribuição de água ou efluente na irrigação por gotejamento que, comprometem a produção agrícola (SOUZA; CORDEIRO; COSTA, 2006).

A minimização dos problemas provocados pelo entupimento de gotejadores tem sido constatada com o aumento da pressão de serviço do sistema de irrigação. Dessa forma, o aumento na magnitude da pressão de serviço interfere positivamente na redução do processo de entupimento de gotejadores devido a maior energia dinâmica no regime de escoamento, dificultando à deposição de sedimentos, bem como a formação de muco microbiano no interior dos gotejadores e das linhas laterais (LESIKAR; WEYNAND; PERSYN, 2004).

O entupimento dos gotejadores pode acarretar mudanças nos valores da pressão de serviço em todo o sistema de irrigação por gotejamento, resultando em redução da vida útil dos equipamentos. Faria et al. (2002) evidenciaram que a redução de vazão dos emissores provocou aumento considerável da pressão na tubulação de distribuição de água do sistema de irrigação por gotejamento estudado. No trabalho desenvolvido por Batista (2007) houve redução na obstrução de gotejadores aplicando água residuária de suinocultura com o aumento da pressão de serviço, sendo as pressões de serviço de 145 e $285 \mathrm{kPa}$ mais recomendadas que as de $75 \mathrm{e}$ $145 \mathrm{kPa}$. 
Diante o exposto, o trabalho objetivou analisar o efeito de pressões de serviço na uniformidade de distribuição de efluente em unidades de irrigação por gotejamento operando com água residuária tratada da castanha de caju.

\section{Material e Métodos}

O trabalho foi realizado na Unidade Experimental de Reuso de Água (UERA) instalada no Parque Zoobotânico da Universidade Federal Rural do Semiárido (UFERSA) em Mossoró-RN, sob coordenadas geográficas 5'12'27” de latitude sul e $37^{\circ} 19^{\prime} 21^{\prime \prime}$ de longitude oeste.

A água residuária resultante do processamento da castanha de caju utilizada no trabalho foi proveniente da Estação de Tratamento de Efluentes (ETE) da empresa AFICEL, localizada em MossoróRN. Deve-se ressaltar que a água residuária bruta foi originada do processo de umidificação e lavagem das castanhas in natura e da lavagem do piso das instalações do empreendimento.

Para os ensaios foi montada uma bancada experimental em alvenaria na UERA com $2,0 \mathrm{~m}$ de largura por $8,0 \mathrm{~m}$ de comprimento, dotada de piso impermeabilizado com declividade de $1 \%$ e possuindo uma canaleta com declividade de $2 \%$ para recirculação do efluente visando à minimização das perdas por evaporação. A jusante desta bancada foi construído um reservatório em alvenaria com capacidade armazenadora para 5,0 $\mathrm{m}^{3}$. No interior da bancada experimental foram montadas quatro unidades de irrigação por gotejamento compostas de: um conjunto motobomba de $1,0 \mathrm{cv}$, um hidrômetro com capacidade para $1,5 \mathrm{~m}^{3} \mathrm{~h}^{-1}$, um filtro de tela com aberturas de $130 \mathrm{~m}$, linha de derivação em PVC de $32 \mathrm{~mm}$ e linhas laterais de polietileno com diâmetro nominal de $16 \mathrm{~mm}$ dotadas de três modelos de gotejadores, conforme apresentado na Figura 1.

Figura 1. Esquema da bancada experimental constituída de quatro unidades de irrigação com três modelos de gotejadores (G1, G2 e G3) operando com água residuária tratada da castanha de caju nas pressões de serviço de 70 (P1), 140 (P2), 210 (P3) e 280 (P4) kPa.

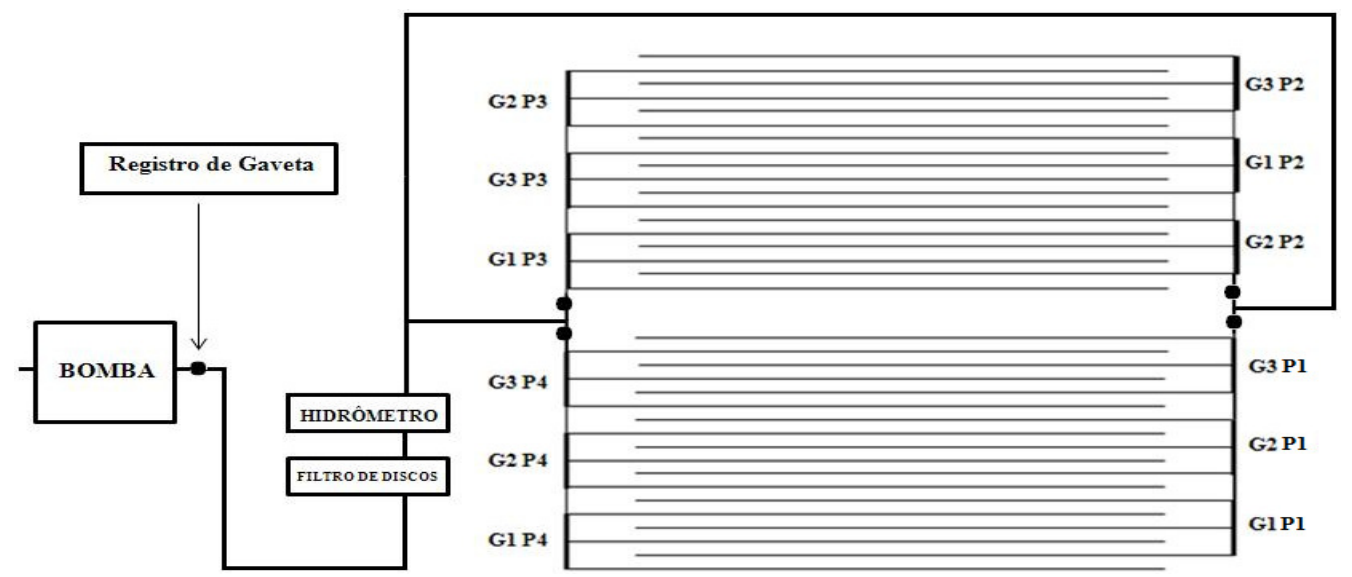

Fonte: Elaboração dos autores.

No início de cada linha de derivação foram instalados registros de gaveta para controle da pressão de serviço nas unidades de irrigação por gotejamento $(70,140,210$ e $280 \mathrm{kPa})$. Na linha de derivação de cada unidade de fertirrigação foram inseridos nove conectores. Para cada modelo de gotejador foram instaladas três linhas laterais com $8 \mathrm{~m}$ de comprimento. Os três tipos de gotejadores avaliados, de acordo com os fabricantes, foram selecionados com base na sua menor suscetibilidade ao entupimento e por serem comercializados no mercado nacional (Tabela 1 ). 
Tabela 1. Características dos gotejadores $(G)$ utilizados nos ensaios: dispositivo de autocompensação (DA), vazão nominal (Q), área de filtração (A), comprimento do labirinto (L), faixa de pressão recomendada (P) e espaçamento entre emissores (EE).

\begin{tabular}{lllllll}
\hline $\mathbf{G}$ & $\mathbf{D A}$ & $\mathbf{Q}\left(\mathbf{L ~ h}^{-\mathbf{1}}\right)$ & $\mathbf{A}\left(\mathbf{m m}^{\mathbf{2}}\right)$ & $\mathbf{L} \mathbf{( m m})$ & $\mathbf{P}(\mathbf{k P a})$ & $\mathbf{E E}(\mathbf{m})$ \\
\hline & & & & & & \\
\hline G1 & Não & 1,6 & 5,0 & 58 & $55-200$ & 0,3 \\
G2 & Sim & 2,0 & 2,0 & 35 & $70-400$ & 1,0 \\
G3 & Sim & 4,0 & 2,0 & 35 & $70-400$ & 1,0 \\
\hline
\end{tabular}

Fonte: Elaboração dos autores.

O experimento foi realizado no período de 11 de março a 20 de abril de 2012. As unidades de irrigação por gotejamento funcionaram, em média, quatro horas por dia até completar $160 \mathrm{~h}$. O coeficiente de uniformidade de distribuição (CUD) foi avaliado a cada 20 h durante o período de aplicação do efluente de 160 h. Para isso, mediu-se a vazão de sete gotejadores de todas as linhas laterais das unidades de irrigação por gotejamento, coletando-se o volume aplicado durante três minutos. A pressão de serviço foi medida diariamente com um manômetro de glicerina graduado de 0 a $400 \mathrm{kPa}$. O cálculo da uniformidade de aplicação do efluente foi obtido com a equação 1 .

em que:

$$
\mathrm{CUD}=\left(\frac{\mathrm{Q}_{\mathfrak{z} \%}}{\mathrm{Q}_{\mathrm{m}}}\right) \times 100
$$

CUD - coeficiente de uniformidade de distribuição, $\%$

Tabela 2. Características físicas, químicas e microbiológicas da água residuária tratada da indústria da castanha de caju e método de determinação.

\begin{tabular}{lcc}
\hline Características & Unidade & Método de determinação \\
\hline $\mathrm{pH}$ & - & Eletrométrico \\
Ferro total $(\mathrm{Fe})$ & $\mathrm{mg} \mathrm{L}^{-1}$ & Espectrofotometria de absorção atômica \\
Manganês total $(\mathrm{Mn})$ & $\mathrm{mg} \mathrm{L}^{-1}$ & Espectrofotometria de absorção atômica \\
Cálcio $\left(\mathrm{Ca}^{2+}\right)$ & $\mathrm{mmol} \mathrm{L}_{\mathrm{c}}^{-1}$ & Titulométrico \\
Magnésio $\left(\mathrm{Mg}^{2+}\right)$ & $\mathrm{mmol} \mathrm{L}^{-1}$ & Titulométrico \\
Sólidos suspensos $(\mathrm{SS})$ & $\mathrm{mg} \mathrm{L}^{-1}$ & Gravimétrico \\
Sólidos dissolvidos $(\mathrm{SD})$ & $\mathrm{mg} \mathrm{L}^{-1}$ & Gravimétrico \\
Coliformes totais $(\mathrm{CT})$ & $\mathrm{NMP} \mathrm{mL}$ & Tubos múltiplos \\
\hline
\end{tabular}

Nota: NMP - Número Mais Provável.

Fonte: Elaboração dos autores.
$\mathrm{Q}_{25 \%}$ - média de $25 \%$ do total dos gotejadores com as menores vazões, $\mathrm{L} \mathrm{h}^{-1}$; e

$\mathrm{Q}_{\mathrm{m}}$ - média das vazões de todos os gotejadores, $\mathrm{L}$ $\mathrm{h}^{-1}$.

As características físicas, químicas e biológicas da água residuária tratada da castanha de caju foram determinadas, também, a cada $20 \mathrm{~h}$ de funcionamento das unidades de irrigação, em conformidade com as recomendações do Standard Methods (APHA, 2005). Essas análises foram realizadas no Laboratório de Análise de Solo, Água e Planta (LASAP) do Departamento de Ciências Ambientais e Tecnológicas e no Laboratório de Inspeção de Produtos de Origem Animal do Departamento de Ciências Animais, ambos pertencentes à UFERSA. Na Tabela 2 estão apresentadas os métodos de determinação das características físicas, químicas e biológicas da água residuária tratada da castanha de caju. 
Na Tabela 3 estão apresentadas as médias e os desvios-padrão das características físicas, químicas e microbiológicas da água residuária tratada da castanha de caju. Os valores de $\mathrm{pH}$, sólidos suspensos (SS) e sólidos dissolvidos (SD) representam risco severo de obstrução de gotejadores, segundo as diretrizes apresentadas por Nakayama, Boman e Pitts (2006). No trabalho apresentado por Batista et al. (2011) o risco de obstrução de gotejadores foi classificado como severo para as características $\mathrm{pH}$ e $\mathrm{SS}$ quando da aplicação de esgoto doméstico terciária, enquanto o risco de obstrução de gotejadores foi classificado como baixo na característica SD. Em outros trabalhos Cunha et al. (2006) e Batista et al. (2007) trabalharam com água residuária da despolpa dos frutos do cafeeiro e constataram riscos de obstrução de gotejadores classificado como baixo, moderado e severo nas características $\mathrm{pH}, \mathrm{SS}$ e $\mathrm{SD}$. Os teores de manganês total $(\mathrm{Mn})$ e ferro total $(\mathrm{Fe})$ apresentam risco de obstrução de gotejadores classificado como moderado como estabelecido por Nakayama, Boman e Pitts (2006). O teor médio de Fe foi inferior ao valor de $1,7 \mathrm{mg} \mathrm{L}^{-1}$ obtido por Batista et al. (2011) em trabalho com esgoto doméstico tratado, que representou também risco moderado de obstrução de gotejadores. No trabalho apresentado por Batista et al. (2011), não foi constatada a presença de $\mathrm{Mn}$, no esgoto doméstico terciário, sendo o risco de obstrução de gotejadores classificado como baixo. Segundo Capra e Scicolone (1998), as concentrações de cálcio $\left(\mathrm{Ca}^{2+}\right)$ e magnésio $\left(\mathrm{Mg}^{2+}\right)$ apresentam risco de obstrução de gotejadores baixo e moderado, respectivamente. No trabalho realizado por Liu e Huang (2009) com esgoto doméstico tratado em sistema de lodo ativado, o risco de obstrução de gotejadores proporcionado por $\mathrm{Ca}^{2+}$ e $\mathrm{Mg}^{2+}$,também, foram classificados com baixo e moderado. Enquanto, no trabalho desenvolvido por Batista et al. (2011) com esgoto doméstico terciário tanto $\mathrm{Ca}^{2+}$ quanto $\mathrm{Mg}^{2+}$ apresentaram baixo risco de obstrução de gotejadores. O nível populacional de coliformes totais (CT) representa baixo risco de obstrução de gotejadores, conforme proposto por Nakayama, Boman e Pitts (2006). Tal resultado foi semelhante ao apresentado por Liu e Huang (2009), onde o risco de obstrução de CT também foi classificado como baixo.

Tabela 3. Valor médio e desvio-padrão das características físicas, químicas e microbiológicas da água residuária tratada da indústria da castanha de caju.

\begin{tabular}{|c|c|c|c|c|c|c|c|}
\hline pH & $\begin{array}{c}\mathbf{F e} \\
\left(\mathrm{mg} \mathrm{L}^{-1}\right)\end{array}$ & $\begin{array}{c}\text { Mn } \\
\left(\mathbf{m g ~ L ^ { - 1 }}\right)\end{array}$ & $\begin{array}{c}\mathrm{Ca}^{2+} \\
\left(\mathbf{m m o l}_{\mathbf{c}} \mathbf{L}^{-1}\right)\end{array}$ & $\begin{array}{c}\mathbf{M g}^{2+} \\
\left(\mathbf{m m o l}_{\mathbf{c}} \mathbf{L}^{-1}\right)\end{array}$ & $\begin{array}{c}\text { SS } \\
\left(\mathbf{m g ~ L ^ { - 1 }}\right)\end{array}$ & $\begin{array}{c}\text { SD } \\
\left(\mathrm{mg} \mathrm{L}^{-1}\right)\end{array}$ & $\begin{array}{c}\mathrm{CT} \\
(\mathrm{NMP} 100 \\
\left.\mathrm{mL}^{-1}\right)\end{array}$ \\
\hline $7,61 \pm 0,55$ & $0,48 \pm 0,06$ & $0,30 \pm 0,04$ & $11,89 \pm 2,32$ & $4,32 \pm 1,59$ & $290 \pm 101$ & $2344 \pm 110$ & $152 \pm 210$ \\
\hline
\end{tabular}

Nota: $\mathrm{pH}=$ potencial hidrogeniônico; $\mathrm{Ca}^{2+}=$ cálcio, $\mathrm{mmol}_{\mathrm{c}} \mathrm{L}^{-1} ; \mathrm{Mg}^{2+}=$ magnésio, $\mathrm{mmol}_{\mathrm{c}} \mathrm{L}^{-1} ; \mathrm{Mn}=$ manganês total, $\mathrm{mg} \mathrm{L}^{-1} ; \mathrm{Fe}=$ ferro total, $\mathrm{mg} \mathrm{L}^{-1} ; \mathrm{SS}=$ sólidos suspensos, $\mathrm{mg} \mathrm{L}^{-1} ; \mathrm{SD}=$ sólidos dissolvidos, $\mathrm{mg} \mathrm{L}^{-1}$; $\mathrm{CT}=$ coliformes totais, $\mathrm{NMP}^{100} \mathrm{~mL}^{-1}$; sendo $\mathrm{NMP}=$ número mais provável.

Fonte: Elaboração dos autores.

Decorrido o período de 160 h de aplicação da água residuária tratada da castanha de caju realizouse a abertura manual dos gotejadores obstruídos para a realização do registro fotográfico da acumulação do biofilme, conforme apresentado na Figura 2. Constatou-se nos gotejadores a presença de biofilme resultante da interação entre agentes físico ( $\mathrm{PH}$, sólidos suspensos), químico (sólidos dissolvidos, cálcio, magnésio e manganês) e biológico (bactérias). A formação desse biofilme está associada a não-realização de abertura de finais de linhas laterais para limpeza, tendo a ausência dessa prática o propósito de potencializar os efeitos do entupimento e, consequentemente, apontar o gotejador menos suscetível ao entupimento, conforme as recomendações de Dazhuang et al. (2009). 
Figura 2. Gotejadores G1 (A), G2 (B) e G3 (c) com a presença de biofilme.

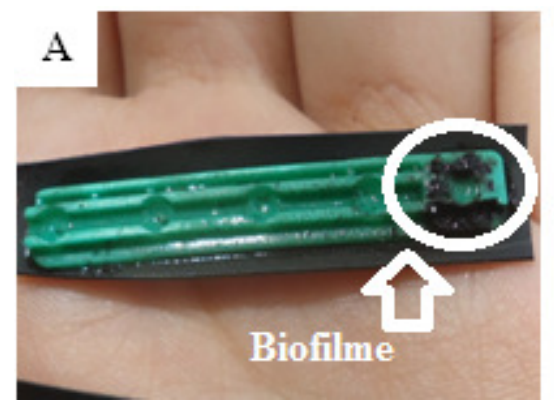

Fonte: Elaboração dos autores.
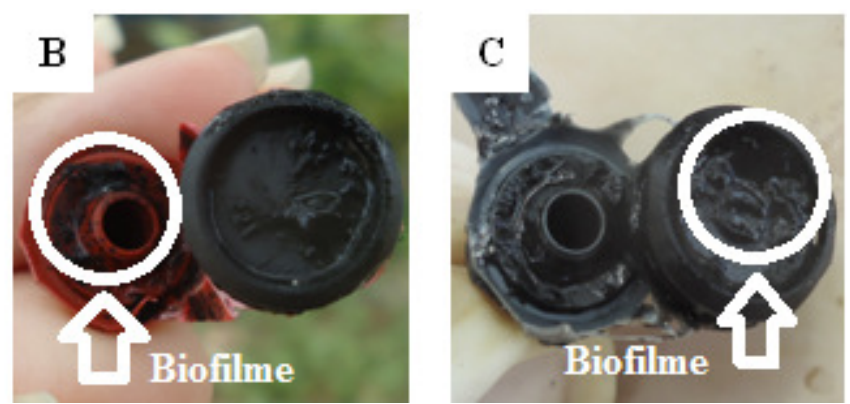

O experimento foi montado em esquema de parcelas subsubdivididas, tendo nas parcelas as pressões de serviço $(70,140,210$ e $280 \mathrm{kPa})$, nas subparcelas os modelos de gotejadores (G1, G2 e G3) e nas subsubparcelas os períodos das avaliações $(0,20,40,60,80,100,120,140$ e 160 h), no delineamento inteiramente casualizado com três repetições. Os dados foram submetidos à análise de variância empregando-se o teste $\mathrm{F}$ a 5\% de probabilidade. Enquanto, as médias foram comparadas utilizando-se o teste Tukey à 5\% de probabilidade.

\section{Resultados e Discussão}

Em função do pequeno comprimento das linhas laterais, a perda de carga distribuída não foi considerada como fator de variação da vazão dos gotejadores. Do mesmo modo, o efeito da temperatura do fluido circulante como causa de perda de uniformidade de aplicação foi desprezado, devido à utilização de gotejadores tipo labirinto, com regime de escoamento turbulento. Ademais, as linhas laterais foram instaladas em nível, eliminando o desnível como fonte de desuniformidade de aplicação. Assim, toda variação de vazão dentro das linhas laterais foi atribuída ao coeficiente de variação de fabricação, inerente a cada gotejador e, posteriormente, ao processo de entupimento de gotejadores. Na Figura 2 estão apresentados os resultados da uniformidade de distribuição (CUD) nas unidades de irrigação com gotejadores G1, G2 e G3 operando com água residuária tratada da castanha de caju sob distintas pressões de serviço.

As unidades de irrigação com gotejador G1, submetidas às pressões de serviço 70, 140, $210 \mathrm{e}$ $280 \mathrm{kPa}$, nos tempos de funcionamento inicial e 160h apresentaram valores do CUD de 96 e 48\%; 97 e 95\%; 93 e 92\%; e 94 e 97\%, respectivamente (Figura 3a). Esses resultados corroboram com os apresentados por Lesikar, Weynand e Persyn (2004) que utilizaram sistemas de irrigação por gotejamento para aplicação de esgoto doméstico tratado e filtrado em filtro de tela de $74 \mu \mathrm{m}$. Constataram nos sistemas de irrigação operando com pressões de serviço de 58 e $78 \mathrm{kPa}$ que 2 e $30 \%$, respectivamente, dos gotejadores avaliados apresentaram entupimento total. Entretanto, no sistema de irrigação que operou com pressão de serviço de $296 \mathrm{kPa}$ nenhum gotejador foi completamente entupido. O gotejador G1, não autocompensante, apresentou os maiores níveis de entupimento em relação a G2 e G3, devido ao maior comprimento de labirinto $(58 \mathrm{~mm})$ e à menor vazão nominal $\left(1,6 \mathrm{~L} \mathrm{~h}^{-1}\right)$; fato similar foi constatado por Cararo et al. (2006), que verificaram aumento linear do nível de entupimento com o comprimento do labirinto. 
Figura 3. Valores médios do coeficiente uniformidade de distribuição (CUD), ao longo do período de operação, nas unidades de irrigação com gotejador G1 (a), G2 (b) e G3 (c) submetidas às pressões de serviço P1 (70 kPa), P2 (140 $\mathrm{kPa}), \mathrm{P} 3(210 \mathrm{kPa})$ e P4 $(280 \mathrm{kPa})$.

A
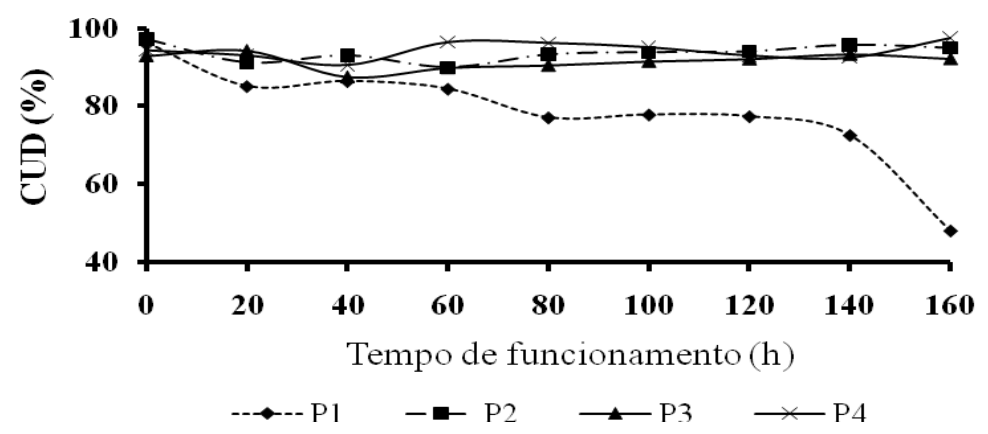

B

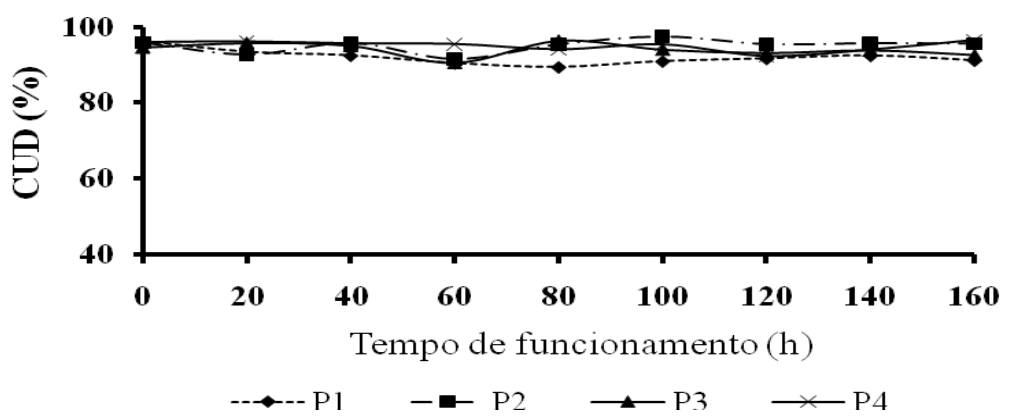

C

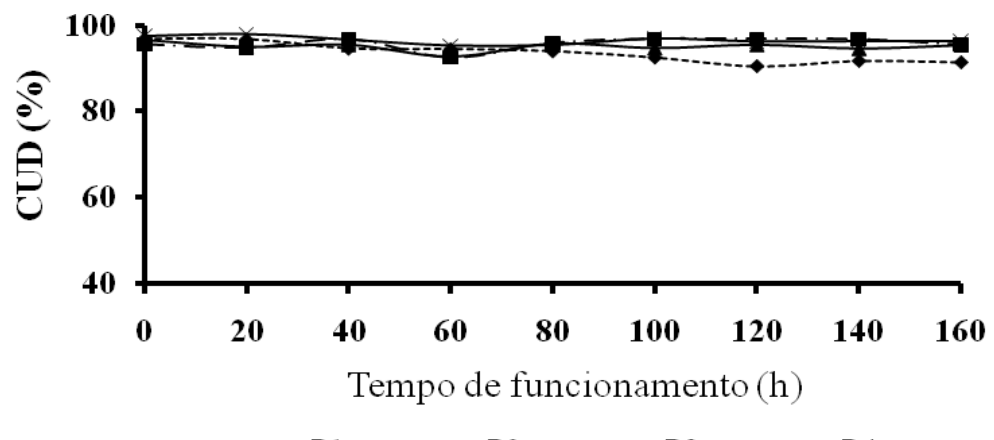

Fonte: Elaboração dos autores.

Segundo Merriam e Keller (1978), os valores de CUD no tempo de operação de $160 \mathrm{~h}$ foram classificados como excelentes ( $>90 \%$ ) nas pressões de serviço 140,210 e $280 \mathrm{kPa}$, porém na pressão de serviço $70 \mathrm{kPa}$ o valor de CUD foi classificado como ruim $(<70 \%)$, indicando elevado número de gotejadores obstruídos na unidade de irrigação. Esses resultados diferem dos obtidos por Batista (2007) com unidades de irrigação por gotejamento operando com água residuária de suinocultura durante $160 \mathrm{~h}$; onde as unidades de irrigação dotadas de gotejador não autocompensante apresentaram 
valores de CUD sempre inferiores a $70 \%$ para as pressões de serviço de 75, 145, 215 e $285 \mathrm{kPa}$.

Já as unidades de irrigação com gotejador G2, submetidas às pressões de serviço 70, 140, $210 \mathrm{e}$ $280 \mathrm{kPa}$, nos tempos de funcionamento inicial e $160 \mathrm{~h}$ apresentaram valores do CUD de 96 e 91\%; 96 e $96 \%$; 95 e $93 \%$; e 96 e 96\%, respectivamente (Figura 3b). O Gotejador G2 apresentou menores níveis de entupimento em relação a $\mathrm{G} 1$, em função do menor comprimento de labirinto $(35 \mathrm{~mm})$ e da maior vazão nominal $\left(2,0 \mathrm{~L} \mathrm{~h}^{-1}\right)$, além disso, o menor valor de área de filtração $\left(2,0 \mathrm{~mm}^{2}\right)$ propicia maior velocidade do escoamento de efluente dificultando a deposição de sedimentos e adesão de muco microbiano (DEHGHANISANIJ et al., 2005; CARARO et al., 2006).

De acordo com Merriam e Keller (1978), todos os valores foram excelentes para o CUD (>90\%). Esses resultados diferem dos obtidos por Batista (2007) com unidades de irrigação por gotejamento operando com água residuária de suinocultura; pois no tempo de funcionamento de $160 \mathrm{~h}$, os valores de CUD obtidos nas pressões de serviço 75 e $145 \mathrm{kPa}$ foram inferiores a $70 \%$, sendo classificados como ruins, enquanto os valores de CUD nas pressões de serviço 215 e 285 se encontram dentro da faixa de 70 a $80 \%$, recebendo a classificação razoável.

Nos tempos de funcionamento inicial e $160 \mathrm{~h}$, as unidades de irrigação com gotejador G3, submetidas às pressões de serviço 70, 140, 210 e $280 \mathrm{kPa}$ apresentaram valores do CUD de 97 e 91\%; 96 e 95\%; 96 e 95\%; e 97 e 96\%, respectivamente (Figura $3 \mathrm{C}$ ). O gotejador G3, assim como o gotejador G2, apresentou menores níveis de entupimento em relação ao gotejador G1, devido ao menor comprimento de labirinto $(35 \mathrm{~mm})$ e à maior vazão nominal $\left(4,0 \mathrm{~L} \mathrm{~h}^{-1}\right)$, corroborando com Cararo et al. (2006).

Todos os valores de CUD foram classificados como excelente $(>90 \%)$, conforme proposto por
Merriam e Keller (1978). Esses resultados diferem dos obtidos por Capra e Scicolone (2004), que estudaram o desempenho hidráulico de unidades de irrigação por gotejamento dotadas de quatro tipos de gotejadores, não-autocompensantes, com vazão nominal de 3,8 a 4,0 $\mathrm{L} \mathrm{h}^{-1}$ e abastecidos com esgoto doméstico tratado durante $60 \mathrm{~h}$; onde os valores de CUD nas unidades de irrigação oscilaram de 0 a $77 \%$.

A maior suscetibilidade ao entupimento do gotejador G1, em relação os gotejadores G2 e G3 na pressão de serviço P1 (70 kPa), está associada ao maior comprimento de labirinto e menor vazão; nessas condições a velocidade do escoamento de efluente no interior do emissor é menor, favorecendo tanto a deposição de partículas quanto a adesão de bactérias formadoras de biofilme, corroborando assim com os resultados apresentado por Dehghanisanij et al. (2005), Dazhuang et al. (2009), Duran-Ros et al. (2009), Liu e Huang (2009).

$\mathrm{Na}$ Tabela 4, encontra-se o resumo da análise de variância do CUD das unidades de irrigação com gotejadores G1, G2 e G3 sob distintas pressões de serviço no esquema de parcelas subsubdivididas.

Houve diferença estatística a $1 \%$ de probabilidade pelo teste $\mathrm{F}$ para as fontes de variação pressão de serviço $(\mathrm{P})$, tipo de gotejador $(\mathrm{G})$, interação PxG, tempo de funcionamento $(T)$, interação PxT, interação GxT e interação PxGxT. Esses resultados corroboram com os obtidos por Batista (2007) em sistemas de irrigação por gotejamento operando com água residuária de suinocultura sob pressões de serviço, onde a interação PxGxT também foi significativa à $1 \%$ pelo teste $\mathrm{F}$.

Os valores dos coeficientes de variação da parcela, subparcela e subsubparcelas foram de 2,67; 2,13; e 2,71\%. Segundo Pimentel Gomes (2009), em experimentos de campo, se o coeficiente de variação for inferior a $10 \%$ considera-se o mesmo como baixo, ou seja, o experimento tem alta precisão. 
Tabela 4. Resumo da análise de variância obtidas da variável CUD, no esquema de parcelas subsubdivididas.

\begin{tabular}{lcc}
\hline Fonte de variação & $\begin{array}{c}\text { Grau de } \\
\text { liberdade }\end{array}$ & $\begin{array}{c}\text { Quadrado médio } \\
\text { CUD }\end{array}$ \\
\hline Pressão de serviço (P) & 3 & $917,75^{* *}$ \\
Resíduo (a) & 6 & 6,17 \\
Tipo de gotejador (G) & 2 & $986,19^{* *}$ \\
P x G & 6 & $355,39^{* *}$ \\
Resíduo (b) & 16 & 3,92 \\
Tempo de funcionamento (T) & 8 & $73,52^{* *}$ \\
P x T & 24 & $77,30^{* *}$ \\
G x T & 16 & $31,08^{* *}$ \\
P x G x T & 48 & $44,88^{* *}$ \\
Resíduo (c) & 194 & 6,35 \\
CV (\%) parcela & & 2,67 \\
CV (\%) subparcela & & 2,13 \\
CV (\%) subsubparcela & & 2,71 \\
\hline
\end{tabular}

**F significativo a $1 \%$ de probabilidade. $\mathrm{CV}=$ coeficiente de variação.

Fonte: Elaboração dos autores.

Estão apresentados na Tabela 4 os valores médios da variável CUD das unidades de irrigação para o fator gotejador dentro de cada nível de tempo de funcionamento e cada nível de pressão de serviço operando com água residuária tratada da castanha do caju. Ao longo das avaliações do CUD, constatase a desobstrução aleatória de alguns gotejadores, particularmente devido a possíveis movimentos bruscos sobre as linhas laterais, conforme descrito por Cunha et al. (2006).

Estabelecendo comparação entre as médias da variável CUD seguidas de pelo menos uma mesma letra minúscula nas colunas da Tabela 5 , constatase que: na pressão de serviço de $70 \mathrm{kPa}$, o CUD da unidade de irrigação com gotejador G1, diferiu do CUD das unidades de irrigação com gotejadores G2 e G3, a partir do tempo de funcionamento de $20 \mathrm{~h}$. Na pressão de serviço de $210 \mathrm{kPa}$, verificou-se que o CUD das unidades de irrigação com gotejador G1, diferiu do CUD das unidades com gotejadores G2 e G3, nos tempos de funcionamento de 40 e $80 \mathrm{~h}$. Na pressão de serviço $280 \mathrm{kPa}$, o CUD da unidade de irrigação com gotejador G1, diferiu do CUD da unidade de irrigação com gotejador G3, no tempo de funcionamento de 20h. Para a pressão de serviço
$280 \mathrm{kPa}$, nota-se que o CUD da unidade de irrigação com gotejador G1, diferiu do CUD das unidades de irrigação com gotejadores G2 e G3, no tempo de funcionamento de $40 \mathrm{~h}$. No trabalho realizado por Batista (2007), verifica-se que o CUD da unidade de irrigação com gotejador não autocompensante $(2,0$ $\mathrm{L} \mathrm{h}^{-1}$ ), operando na pressão de serviço de $75 \mathrm{kPa}$, diferiu do CUD das demais unidades de irrigação, a partir do tempo de funcionamento de $120 \mathrm{~h}$.

Comparando as médias da variável CUD seguidas de pelo menos uma mesma letra maiúscula nas linhas da Tabela 5, nota-se que: a partir do tempo de funcionamento de $20 \mathrm{~h}$, o CUD da unidade de irrigação com gotejador G1 submetida à pressão de serviço de $70 \mathrm{kPa}$ diferiu do CUD das unidades de irrigação submetidas às pressões de serviço de 140 , 210 e $280 \mathrm{kPa}$; a partir do tempo de funcionamento de 80 h, o CUD da unidade de irrigação com gotejador G2 submetida à pressão de serviço de $70 \mathrm{kPa}$ diferiu do CUD das unidades de irrigação submetidas às pressões de serviço de 140, 210 e 280 $\mathrm{kPa}$; e somente no tempo de funcionamento de 120 h, o CUD da unidade de irrigação com gotejador G3 submetida à pressão de serviço de $70 \mathrm{kPa}$ diferiu do CUD das unidades de irrigação submetidas às pressões de serviço de 140 e $280 \mathrm{kPa}$. 
Tabela 5. Valores médios da variável CUD (\%) das unidades de irrigação para o fator gotejador dentro de cada nível de tempo de funcionamento e cada nível de pressão de serviço.

\begin{tabular}{|c|c|c|c|c|c|}
\hline \multirow{2}{*}{$\begin{array}{l}\text { Tempo de } \\
\text { funcionamento }(\mathrm{h})\end{array}$} & \multirow{2}{*}{ Gotejador } & \multicolumn{4}{|c|}{ Pressão de serviço* } \\
\hline & & $\mathrm{P} 1(70 \mathrm{kPa})$ & $\mathrm{P} 2(140 \mathrm{kPa})$ & P3 $(210 \mathrm{kPa})$ & $\mathrm{P} 4(280 \mathrm{kPa})$ \\
\hline \multirow{3}{*}{0} & G1 & $96,14 \mathrm{aA}$ & $97,20 \mathrm{aA}$ & $92,98 \mathrm{aA}$ & $94,33 \mathrm{aA}$ \\
\hline & G2 & $96,14 \mathrm{aA}$ & $95,89 \mathrm{aA}$ & $94,55 \mathrm{aA}$ & $95,89 \mathrm{aA}$ \\
\hline & G3 & $96,75 \mathrm{aA}$ & $95,57 \mathrm{aA}$ & $96,53 \mathrm{aA}$ & $97,56 \mathrm{aA}$ \\
\hline \multirow{3}{*}{20} & G1 & $85,07 \mathrm{bB}$ & $91,14 \mathrm{aA}$ & $95,80 \mathrm{aA}$ & $93,04 \mathrm{bA}$ \\
\hline & G2 & $93,38 \mathrm{aA}$ & $92,66 \mathrm{aA}$ & $96,93 \mathrm{aA}$ & $96,05 \mathrm{abA}$ \\
\hline & G3 & $96,69 \mathrm{aA}$ & $94,78 \mathrm{aA}$ & $96,62 \mathrm{aA}$ & $97,90 \mathrm{aA}$ \\
\hline \multirow{3}{*}{40} & G1 & $86,37 \mathrm{bB}$ & $92,99 \mathrm{aA}$ & $87,49 \mathrm{bB}$ & $90,64 \mathrm{bAB}$ \\
\hline & G2 & $92,45 \mathrm{aA}$ & $95,73 \mathrm{aA}$ & $94,99 \mathrm{aA}$ & $95,56 \mathrm{aA}$ \\
\hline & G3 & $94,57 \mathrm{aA}$ & $96,70 \mathrm{aA}$ & $95,40 \mathrm{aA}$ & $96,59 \mathrm{aA}$ \\
\hline \multirow{3}{*}{60} & G1 & $84,40 \mathrm{bC}$ & $89,92 \mathrm{aB}$ & $89,86 \mathrm{aB}$ & $96,40 \mathrm{aA}$ \\
\hline & G2 & $90,41 \mathrm{aA}$ & $89,92 \mathrm{aA}$ & $90,39 \mathrm{aA}$ & $95,42 \mathrm{aA}$ \\
\hline & G3 & $94,43 \mathrm{aA}$ & $92,63 \mathrm{aA}$ & $92,67 \mathrm{aA}$ & $95,18 \mathrm{aA}$ \\
\hline \multirow{3}{*}{80} & G1 & $77,05 \mathrm{bC}$ & $93,24 \mathrm{aAB}$ & $90,50 \mathrm{bB}$ & $96,21 \mathrm{aA}$ \\
\hline & $\mathrm{G} 2$ & $89,40 \mathrm{aB}$ & $95,37 \mathrm{aA}$ & $96,36 \mathrm{aA}$ & $94,04 \mathrm{aAB}$ \\
\hline & G3 & $93,95 \mathrm{aA}$ & $95,86 \mathrm{aA}$ & $95,68 \mathrm{aA}$ & $95,92 \mathrm{aA}$ \\
\hline \multirow{3}{*}{100} & G1 & $77,80 \mathrm{bB}$ & $93,83 \mathrm{aA}$ & $91,53 \mathrm{aA}$ & $95,11 \mathrm{aA}$ \\
\hline & G2 & $90,93 \mathrm{aB}$ & $97,46 \mathrm{aA}$ & $93,96 \mathrm{aAB}$ & $95,30 \mathrm{aAB}$ \\
\hline & G3 & $92,48 \mathrm{aA}$ & $96,78 \mathrm{aA}$ & $94,63 \mathrm{aA}$ & $96,85 \mathrm{aA}$ \\
\hline \multirow{3}{*}{120} & G1 & $77,34 \mathrm{bB}$ & $94,02 \mathrm{aA}$ & $92,14 \mathrm{aA}$ & $93,03 \mathrm{aA}$ \\
\hline & G2 & $91,64 \mathrm{aA}$ & $95,44 \mathrm{aA}$ & $93,05 \mathrm{aA}$ & $92,29 \mathrm{aA}$ \\
\hline & G3 & $90,44 \mathrm{aB}$ & $94,02 \mathrm{aA}$ & $95,42 \mathrm{aAB}$ & $96,15 \mathrm{aA}$ \\
\hline \multirow{3}{*}{140} & G1 & $72,52 \mathrm{bB}$ & $95,75 \mathrm{aA}$ & $93,37 \mathrm{aA}$ & $92,49 \mathrm{aA}$ \\
\hline & G2 & $92,41 \mathrm{aA}$ & $95,69 \mathrm{aA}$ & $93,77 \mathrm{aA}$ & $93,96 \mathrm{aA}$ \\
\hline & G3 & $91,70 \mathrm{aA}$ & $96,68 \mathrm{aA}$ & $94,52 \mathrm{aA}$ & $96,24 \mathrm{aA}$ \\
\hline \multirow{3}{*}{160} & G1 & $48,04 \mathrm{bC}$ & $94,95 \mathrm{aAB}$ & $92,22 \mathrm{aB}$ & $97,43 \mathrm{aA}$ \\
\hline & G2 & $91,14 \mathrm{aB}$ & $95,61 \mathrm{aAB}$ & $92,53 \mathrm{aAB}$ & $96,44 \mathrm{aA}$ \\
\hline & G3 & $91,37 \mathrm{aA}$ & $95,46 \mathrm{aA}$ & $95,31 \mathrm{aA}$ & $96,27 \mathrm{aA}$ \\
\hline
\end{tabular}

* Médias seguidas de pelo menos uma mesma letra minúscula nas colunas para cada tempo de funcionamento e maiúsculas nas linhas para cada pressão de serviço não diferem entre si, a 5\% de probabilidade, pelo teste de Tukey.

Fonte: Elaboração dos autores.

\section{Conclusões}

1. A combinação gotejador G3 e pressão de serviço de $140 \mathrm{kPa}$ proporcionou níveis excelentes da uniformidade de distribuição de efluente nas unidades de irrigação operando com água residuária tratada da castanha de caju.

2. Para aplicação de água residuária tratada da castanha de caju não é recomendada o uso de gotejadores de baixa vazão nominal $\left(\leq 1,6 \mathrm{~L} \mathrm{~h}^{-1}\right) \mathrm{e}$ maior comprimento de labirinto ( $\geq 58 \mathrm{~mm})$.

\section{Referências}

AMERICAN PUBLIC HEALTH ASSOCIATION APHA. Standard methods for the examination of water and wastewater. 21. ed. Washigton: APHA/AWWA/ WEF, 2005. $1268 \mathrm{p}$.

BATISTA, R. O. Desempenhos de sistemas de irrigação por gotejamento utilizado na aplicação de água residuária de suinocultura. 2007. Tese (Doutorado em Engenharia Agrícola) - Universidade Federal de Viçosa, Viçosa, MG. 
BATISTA, R. O.; COSTA, F. G. B.; LOPES, H. S. S.; COELHO, D. C. L.; COSTA PAIVA, M. R. F. Efeito das características do esgoto doméstico na uniformidade de aplicação de sistemas de irrigação por gotejamento. Revista Caatinga, Mossoró, v. 24, n. 4, p. 137-144, 2011.

BATISTA, R. O.; MATOS, A. T.; CUNHA, F. F.; Lo MONACO, P. A. Formação de biofilme em gotejadores aplicando água residuária da despolpa dos frutos do cafeeiro. Acta Scientiarum. Agronomy, Maringá, v. 29, n. 3, p. 367-371, 2007.

CAPRA, A.; SCICOLONE, B. Emitter and filter tests for wastewater reuse by drip irrigation. Agricultural Water Management, Amsterdam, v. 68, n. 2, p. 135-149, 2004.

Water quality and distribution uniformity in drip/trickle irrigation systems. Journal of Agricultural Engineering Research, London, v. 70, n. 4, p. 355-365, 1998.

CARARO, D. C.; BOTREL, T. A.; HILLS, D. J.; LEVERENZ, H. L. Analysis of clogging in drip emitters during wastewater irrigation. Applied Engineering in Agriculture, St. Joseph, v. 22, n. 2, p. 251-257, 2006.

CHEDEVILLE, O.; DEBACQ, M.; PORTE, C. Removal of phenolic compounds present in olive mill wastewaters by ozonization. Desalination, Amsterdan, v. 249, n. 2, p. 865-869, 2009.

CUNHA, F. F.; MATOS, A. T.; BATISTA, R. O.; Lo MONACO, P. A. Uniformidade de distribuição em sistemas de irrigação por gotejamento utilizando água residuária da despolpa dos frutos do cafeeiro. Acta Scientiarum. Agronomy, Maringá, v. 28, n. 1, p. 143-147, 2006.

DAZHUANG, Y.; ZHIHUI, B.; ROWAN, M.; LIKUN, G.; SHUMEI, R.; PEILING, Y. Biofilm structure and its influence on clogging in drip irrigation emitters distributing reclaimed wastewater. Journal of Environmental Sciences, Beijing, v. 21, n. 6, p. 834-841, 2009.

DEHGHANISANIJ, H.; YAMAMOTO, T.; OULD AHMAD, B. V.; FUJIYAMA, H.; MIYAMOTO, K. The effect of chlorine on emitter clogging induced by algae and protozoa and the performance of drip irrigation. Transaction of the ASAE, St. Joseph, v. 48, n. 2, p. 519527, 2005.
DURAN-ROS, M.; PUIG-BARGUE'S, J.; ARBAT, G.; BARRAGA'N, J.; RAMI'REZ DE CARTAGENA, F. Effect of filter, emitter and location on clogging when using effluents. Agricultural Water Management, Amsterdam, v. 96, n. 1, p. 67-79, 2009.

FARIA, L. F.; COELHO, R. D.; FLECHA, P. A. N.; ROBLES, W. G. R.; VÁSQUEZ, M. A. N. Entupimento de gotejadores e seu efeito na pressão da rede hidráulica de um sistema de microirrigação. Revista Brasileira de Engenharia Agrícola e Ambiental, Campina Grande, v. 6, n. 2, p. 195-198, 2002.

LESIKAR, B. J.; WEYNAND, V. L.; PERSYN, R. A. Evaluation of the application uniformity of subsurface drip distribution systems. In: ON - SITE WASTEWATER TREATMENT, 10., Sacramento, 2004. Proceedings... St. Joseph: ASAE, 2004. p. 73-83. (Paper n. 701P0104).

LIU, H.; HUANG, G. Laboratory experiment on drip emitter clogging with fresh water and treated sewage effluent. Agricultural Water Management, Amsterdam, v. 96, n. 5, p. 745-756, 2009.

LOPES, M. S. S.; OLIVEIRA, P. C. C.; ANDRADE, M. V. F.; ARAÚJO, R. S.; MARINHO, G.; RODRIGUES, K. Remoção de macronutrientes de efluente da indústria de castanha de caju por uso de reator aeróbio em batelada com inoculo fúngico. Revista Engenharia Sanitária e Ambiental, Rio de Janeiro, v. 16, n. 1, p. 17-26, 2011.

MERRIAM, J. L.; KELLER, J. Farm irrigation system evaluation: a guide for management. Logan: Utah State University, 1978. $271 \mathrm{p}$.

NAKAYAMA, F. S.; BOMAN, B. J.; PITTS, D. Maintenance. In: LAMM, F. R.; AYARS, J. E.; NAKAYAMA, F. S. (Ed.). Microirrigation for crop production: design, operation, and management. Amsterdam: Elsevier, 2006. cap. 11, p. 389-430.

PIMENTEL GOMES, F. Curso de estatística experimental. 15. ed. Piracicaba: FEALQ, 2009. 451 p.

SOUZA, J. A. A.; BATISTA, R. O.; RAMOS, M. M.; SOARES, A. A. Contaminação microbiológica do perfil do solo com esgoto sanitário. Acta Scientiarum. Technology, Maringá, v. 33, n. 1, p. 5-8, 2011.

SOUZA, J. A. A.; CORDEIRO, E. A.; COSTA, E. L. Aplicação de hipoclorito de sódio para recuperação de gotejadores entupidos em irrigação com água ferruginosa. Revista Brasileira de Engenharia Agrícola e Ambiental, Campina Grande, v. 10, n. 1, p. 5-9, 2006. 
